\title{
CONSTRUCTIVISMO EPISTEMOLÓGICO: ENTRE RAWLS Y HABERMAS
}

\begin{abstract}
- e propongo defender en este ensayo una cierta concepción sobre el conocimiento moral que llamo «constructivismo epistemológico». Se trata de una concepción según la cual la práctica social es un medio apto para tal conocimiento.

La defensa de este enfoque la haré contrastando el pensamiento de dos grandes filósofos que según creo se aproximan a la posición correcta: John Rawls y Jürgen Habermas. Sin embargo, creo que ninguno de ambos pensadores aciertan a formular exactamente esa posición. Como su leve alejamiento del blanco se produce en direcciones opuestas, el contraste entre Rawls y Habermas es sumamente ilustrativo, pues permite inferir el curso teórico apropiado.

1. Como se sabe, es sumamente controvertido cuál es la auténtica posición meta-ética de Rawls, vale decir cuál es para este autor el fundamento final de sus dos famosos principios de justicia (el principio de prioridad de la libertad, que prescribe una distribución igualitaria de derechos civiles y políticos y el principio de diferencia que sólo permite desigualdades económicas y sociales en la medida en que estén adscritas a cargos abiertos a todos y que vayan en beneficio de los miembros menos favorecidos de la sociedad).

La incertidumbre sobre la posición meta-ética de Rawls está producida por el hecho de que en la teoría de la justicia apela para fundamentar sus dos principios de justicia a prácticamente todos los recursos, excepto el teológico, que se han ensayado en la historia de la filosofía para fundamentar intersubjetivamente principios morales: el consentimiento, el auto-interés, las intuiciones y los presupuestos formales del razonamiento moral. Es más, la obra de Rawls ha estimulado a diversos filósofos a desarrollar con más profundidad cada una de estas alternativas de justificación moral ${ }^{1}$.
\end{abstract}

${ }^{1}$ Gauthier: Desde el punto de vista del autointerés, Morals by agreement, Oxford, 1986. Desde el consentimiento: a) D. Richards, A theory of reasons for action, Oxford, 1971; b) Buchanan, James and Tullock Gordon, The calculus of consent, Michigan, 1962. Morton White, desde el punto de vista de las intenciones: What is and What ought to be done, Oxford University Press, 1981. 
El recurso al consentimiento es el más explícito, dado la insistencia de Rawls en afiliar su teoría al contractualismo. Como se sabe, él sostiene que sus dos principios de justicia son principios que serían aceptados por unanimidad en una situación hipotética que él llama «posición originaria»: ella se define por rasgos de los sujetos -son racionales, auto-interesados, conocen los hechos generales pero están bajo un «velo de ignorancia» respecto de los hechos particulares de ellos y de su sociedad -y por algunos rasgos del contexto social- lo que Rawls llama «las circunstancias de justicia», especialmente la escasez moderada de recursos.

Pero también en esta presentación Rawls parece recurrir al auto-interés como fundamento de sus principios, cuando presenta su construcción como un teorema en la teoría de la decisión racional ${ }^{2}$. La concepción de racionalidad como maximización de la propia utilidad empleada en esta teoría, y también en importantes áreas teóricas de la economía, parece estar subyacente a la posición originaria, ya que los sujetos eligen los principios de justicia, siendo egoístas racionales, sobre la base de su interés en maximizar su acceso a «bienes primarios» (aquellos bienes, como la libertad y los recursos económicos, que todos quieren cualquiera sea su plan de vida) y empleando el principio de prudencia racional denominado «maximin» (el que prescribe elegir en situaciones de incertidumbre el estado de cosas cuya peor posición sea menos mala que las peores posiciones de arreglos alternativos).

Asimismo, el recurso a las intuiciones por parte de Rawls es también explícito. Todos sabemos que él sostiene que la posición originaria permite derivar principios que serían aceptables en un equilibrio reflexivo que se obtiene luego de ajustes mutuos entre principios generales que parecen prima facie plausibles e intuiciones sobre la justicia e injusticia de soluciones para casos específicos, abandonando las soluciones más débiles que no se compadecen con principios plausibles y reformulando los principios que no permiten homologar las intuiciones más fuertes. Dado que Rawls dice explícitamente que la posición originaria se manipula para que arroje resultados aceptables ${ }^{3}$, las intuiciones parece ser el último tribunal de apelación sobre la validez de sus principios; al menos sus intuiciones y las de su lector ${ }^{4}$. Incluso en

${ }^{2}$ J. Rawls, Teoría de la justicia, Fondo de Cultura Económica, España, 1978.

${ }^{3}$ Op. cit.

${ }^{4}$ Op. cit. 
sus últimos trabajos Rawls parece extender $\mathrm{y}$, tal vez modificar la relevancia de las intuiciones, ya que en ellos Rawls declara que el papel de la teoría política es llegar a un «consenso sobrepuesto» entre concepciones vigentes en una cultura democrática, cosa que él cree que está expresado en sus principios. Sin embargo, no vamos a ocuparnos aquí de estas últimas obras de Rawls, en la que parece haber modificado posiciones cruciales defendidas en La teoría de la justicia ${ }^{5}$.

Por último, el recurso menos explícito que emplea Rawls para fundamentar sus principios es el que consiste en acudir a presupuestos formales del discurso moral. No obstante, este recurso sale también a la superficie en algunas ocasiones: cuando Rawls sostiene que los principios de justicia deben satisfacer ciertas restricciones formales -como las de generalidad, universalidad, publicidad, finalidad, etc.-, cuando sostiene que el rol de la teoría moral es describir nuestra capacidad moral, de juzgar cosas como justas o injustas y de apoyarnos en razones (46), y que cada uno tiene en sí mismo la forma completa de una concepción moral (50), cuando dice que las condiciones de la posición originaria son aceptadas de hecho por nosotros (21), cuando sostiene que la derivación de principios de la posición originaria es un caso de justicia procesal pura (120), etc. Aunque otros trabajos de Rawls quedan fueran de los límites de esta comparación, no puede dejar de mencionarse que en su trabajo de transición Kantian Constructivism, el autor es explícito en que los procedimientos por los que los primeros principios son elegidos deben ser adecuadamente fundados en el razonamiento práctico, que no hay otros hechos morales aparte del procedimiento de construcción de los principios, y que la verdad de los juicios morales está consiguientemente definida por tal procedimiento.

A pesar de las apariencias e interpretaciones corrientes, creo que la reconstrucción más plausible del punto de vista metaético subyacente a La teoría de la justicia es la que da exclusividad justificatoria a este último recurso, a los presupuestos formales del razonamiento moral, interpretando los otros recursos como derivados de aquél. Creo que esta reconstrucción no sólo permite absorber adecuadamente las afirmaciones sobre aspectos formales del discurso moral a las que acabo de aludir, sino que también permite explicar las referencias a los otros recursos justificatorios mejor que si se diera prioridad a cualquiera de éstos,

\footnotetext{
${ }^{5}$ Op. cit.
} 
y sobre todo permite obviar las claras deficiencias de tales otros recursos justificatorios.

En efecto, creo que la idea de un consentimiento que justifique arreglos sociales de los que surjan obligaciones presupone la existencia de principios válidos que toman a decisiones o acciones voluntarias como antecedentes de consecuencias normativas, por lo que el consentimiento no puede servir para justificar principios últimos ${ }^{6}$. Por otro lado, como muchas veces se ha dicho ${ }^{7}$, un consentimiento hipotético no puede proveer una justificación categórica de principios o instituciones. En relación a la elección racional fundada en el auto-interés, además de sus inconvenientes intrínsecos que creo difícilmente superables ${ }^{8}$, el recurso a ella parece estar neutralizado por Rawls debido a que, si bien los seres en la posición originaría son egoístas, el velo de ignorancia les impide conocer quiénes son y cuáles son sus intereses. Si alguien es auto-interesado pero no sabe quién es y qué quiere, la referencia del prefijo «auto» desaparece. Como dice Hare ${ }^{9}$ la presuposición de egoísmo y de ignorancia es equivalente a la de imparcialidad y conocimiento. Por último, en cuanto al recurso a las intuiciones en el marco del equilibrio reflexivo, parece poco plausible cuando las intuiciones no se toman como percepciones de alguna realidad ulterior, sino como una materia prima básica que bien puede ser la resultante de un condicionamiento social, cultural, propagandístico, etcétera. Esto se agrava si no se reconoce a los principios generales una fuente independiente de plausibilidad, por lo que sólo quedan las intuiciones girando en el vacío.

En cambio, cuando partimos de la base de que en el Rawls de La teoría de la justicia el fundamento justificatorio básico está dado por presupuestos formales del razonamiento moral (aunque no puede excluirse, por más que Rawls ahora lo niegue, que ellos se unan a presupuestos valorativos sustantivos como la autonomía) todas las piezas comienzan a encajar adecuadamente. La posición originaria se convierte en una dramatización de esos presupuestos formales, o en un recurso de representación como el mismo Rawls dice ${ }^{10}$. El contrato hipotético hace alusión

${ }^{6}$ C. Nino, Los límites de la responsabilidad penal, Astrea, Buenos Aires.

${ }^{7}$ R. Dworkin, en Norman Daniels (eds.), Reading Rawls, Basil Blackwell, Oxford, 1975.

${ }^{8}$ C. Nino, Ética y Derechos Humanos, Paidós, Buenos Aires, 1985.

${ }^{9}$ Hare, «Rawls’s Theory of Justice», en Norman Daniels (eds.), Reading Rawls, Basil Blackwell, Oxford, 1975.

${ }^{10}$ J. Rawls, Teoría de la justicia, Fondo de Cultura Económica. 
a un presupuesto de razonamiento moral según el cual los principios generales, universales, etcétera, son válidos cuando serían unánimemente aceptables por todos los interesados en ciertas condiciones ideales. El recurso al auto-interés una vez combinado con el velo de ignorancia tiene sólo el valor heurístico de permitirnos determinar más fácilmente qué restricciones impone a nuestro razonamiento moral la exigencia subyacente de imparcialidad, que, junto con las de racionalidad y conocimiento de los hechos relevantes, es una de esas condiciones ideales. Finalmente, las intuiciones pueden tener un valor indicativo si se las considera como expresiones de la «forma de la teoría moral que cada uno tiene en sí mismo», y sirven, por tanto, como indicios de la aplicación de presupuestos formales del razonamiento a juicios sobre casos concretos.

Si esta visión de la teoría de Rawls, que la aproxima a la de Kant mucho más estrechamente que los enfoques alternativos, fuera plausible, podríamos sostener que ella incluye una cierta caracterización de la verdad en materia moral: un juicio moral es verdadero cuando él deriva de un principio que sería aceptado en la posición originaria, vale decir él deriva de un principio general, universal, público, final, etc., que sería aceptado unánimemente en condiciones de imparcialidad, racionalidad, conocimiento de los hechos relevantes, etc. (aquí por supuesto, reemplazarnos los recursos heurísticos de Rawls por las que consideramos que son las verdaderas exigencias que ellos están destinados a captar y a sustituir operativamente).

Rawls no es para nada explícito sobre cuál es el método o el procedimiento apropiado sobre la forma de conocer este tipo de verdad moral. Aparentemente, él asume que la reflexión individual como la que él mismo emprende en La teoría de la justicia es un método adecuado para tener acceso a la verdad en materia moral, por lo menos en el ámbito de la justicia.

Tal vez el equilibrio reflexivo, una vez que es descalificado como un procedimiento constitutivo de la verdad moral, puede ser plausiblemente concebido como un posible método de acceso a la verdad en el marco de la reflexión individual. En efecto, el ajuste recíproco entre principios generales y convicciones particulares ya no oscila en el vacío cuando concebimos a las intuiciones no sólo como juicios particulares que deben deducirse de los principios generales que terminemos aceptando, sino que, por su carácter más espontáneo que el de la formulación de tales principios, pueden ser indicativas de la aplicación de presupuestos formales del razonamiento que sirven de filtro de principios inválidos. Por ejemplo, la intuición de que el dolor que se le 
causa a Juan no puede estar justificado sólo por el mayor placer que ello provoca a Pedro, puede ser indicativa de que nuestro razonamiento práctico presupone una construcción de la imparcialidad a partir de la separabilidad de las personas, lo que quizás permite descalificar un principio agregativo como el del utilitarismo. Es también posible, por supuesto, que una intuición particular que se opone a un principio que parece superar los filtros formales no sea indicativa de lo contrario, por lo que debería ser abandonada en favor del principio.

Sea o no a través de este método de equilibrio, lo cierto es que parece que en el marco del enfoque de Rawls la reflexión individual permite acceder a la verdad moral, definida a partir de la satisfacción de ciertas exigencias como las de imparcialidad o universalidad.

Esto no excluye, por supuesto, que el intercambio de opiniones con otros no tenga en la teoría de Rawls algún valor espistémico. Lo contrario implicaría negar que, por ejemplo, las reflexiones que el propio Rawls hace en su libro tengan algún valor para nosotros. Por cierto, que todos nos beneficiamos con el resultado de la reflexión de otros, ya que se supone que compartimos, por lo menos parcialmente, los mismos presupuestos y esquemas conceptuales y las mismas posibilidades de acceso a los hechos por medio de la observación. Pero probablemente Rawls mantendría que uno debe guiarse finalmente por el resultado de la propia reflexión, ya que él parece adoptar, como Kant, un concepto de autonomía que incluye la idea de que en materia moral cada uno es su propia autoridad epistémica. Dada la estructura de nuestro razonamiento práctico esto parece inevitable, ya que no podemos aceptar los mandatos de otra autoridad -por ejemplo, un legislador- sin reconocerla como tal, y esto implica un juicio de nosotros mismos de que debemos hacer lo que esa autoridad dispone. Obedecer a otro siempre parece implicar seguir nuestras propias razones, sean éstas morales o prudenciales ${ }^{11}$.

Cuando Rawls trata el tema de la justificación de la democracia, entendida como regla de la mayoría, pone más en claro su individualismo epistemológico. Allí sostiene terminantemente que «no hay nada que abone la opinión de que lo que la mayoría quiere es correcto» (pág. 356). Rechaza la posibilidad de aplicar el teorema de Condorcet para justificar que cuanto más gente apoya una solución más probable es que ella sea correcta, sosteniendo

${ }^{11}$ C. Nino, La validez del derecho, Astrea, Buenos Aires, 1985. 
que ello presupone que es más probable que la opinión de cada partícipe en la decisión sea correcta que incorrecta y que los votos de las diferentes personas sean independientes o que no se influyan mutuamente; Rawls opina que ninguna de las dos condiciones se dan necesariamente en un procedimiento democrático.

Sin embargo, Rawls reconoce a continuación que la discusión entre muchas personas tiene efectos beneficiosos, puesto que refrena nuestra parcialidad (no en una discusión ideal en que se supone que los partícipes son imparciales), amplía nuestra perspectiva y nuestros conocimientos y permite detectar errores de razonamiento.

No obstante, es poco claro a qué materia se podría aplicar este beneficio que entraña la discusión colectiva inherente al sistema democrático para la determinación de soluciones correctas. Toda la materia regida por el primer principio referido a la libertad e incluso todo lo que hace al valor de esta última (pág. 356), que está dado por el segundo principio, condiciona al procedimiento de decisión y discusión democrática y no está supeditada a sus resultados. Es cierto que luego Rawls reconoce (pág. 362) que los principios de justicia, sobre todo el de diferencia, dejan abiertas una serie de determinaciones -como el porcentaje de ahorro y el peso relativo de diferentes bienes primarios como el de auto-respeto- y que esas indeterminaciones deben ser resueltas por el procedimiento democrático. Pero en este caso, el mérito de la discusión y decisión democrática no consiste en permitirnos aproximarnos al conocimiento de la solución correcta sino en constituir esa solución correcta como si fuera un caso de justicia procesal pura. No obstante Rawls aclara que no se trata literalmente de un caso de ese tipo ya que no es que el procedimiento defina estrictamente la solución correcta, sino que los que están en desacuerdo con la decisión mayoritaria no pueden convencer a los demás en el marco de la concepción pública de la justicia (pág. 362).

Todo esto es muy confuso, ya que Rawls parece advertir que debe dejar un área de la moral en que la discusión y decisión mayoritaria tienen alguna relevancia para la corrección de las soluciones, aunque oscila entre dar a esa discusión y decisión valor constitutivo o valor epistemológico o ningún valor, por más que estemos obligados a acatar sus resultados por otras razones (dice expresamente que el hecho de que un ciudadano deba cumplir con la decisión mayoritaria no implica que debe considerarla justa y que sería errado para él que supeditara su juicio a ese voto [pág. 360]). 
De cualquier modo, dado que todo lo que hace al primer principio de prioridad de la libertad e incluso al valor de ésta, que está dado por el acceso a los recursos económicos y sociales regulado por el segundo principio, condiciona a la discusión y decisión democrática, no hay duda sobre el individualismo epistemológico de Rawls sobre una amplísima y prioritaria área de la moral. En todo lo que hace a la determinación de los derechos civiles y políticos de los individuos y tal vez incluso a sus derechos económicos y sociales, la reflexión individual es soberana y la discusión y decisión colectiva tiene un valor meramente auxiliar. Esto no debe confundirse, por supuesto, con la relevancia de los procedimientos ideales de decisión constituidos por la posición originaria en sus cuatro estadios: esos procedimientos son constitutivos de la verdad en materia moral, ya que, como vimos, reflejan restricciones formales del razonamiento práctico. Pero a esa verdad se llega, conviene insistir, a través de una reflexión individual efectiva que determine cuál sería el resultado del procedimiento colectivo ideal.

2. Como en el caso de Rawls, para referirme a la posición de Jürgen Habermas tendré en cuenta una sola obra: su largo ensayo Ética del discurso. Notas sobre un programa de fundamentación ${ }^{12}$, en el que expone con claridad no habitual los lineamientos de su posición sobre fundamentación de la ética.

Allí Habermas se apoya en Strawson ${ }^{13}$ para mostrar que la justificación de juicios morales y el reproche basados en ellos es parte de una práctica social que pervade buena parte de nuestra vida y de los intercambios con otros. Es como parte de esa práctica que se predica verdad o falsedad de los juicios morales cosa que no se hace de los mandatos o decisiones. Sin embargo, esta predicación de verdad en el caso de las normas tiene un carácter distinto a la de las proposiciones descriptivas -con lo que el discurso práctico se distingue del teórico-, debido a que las normas se interponen entre los actos de habla y la realidad empírica. Según Habermas entre la existencia de relaciones objetivas y la veracidad de los enunciados aseverativos correspondientes se da una relación interna que no se da entre las relaciones objetivas y las expectativas normativas; esta diferencia es lo que justifica que las condiciones de validez de los juicios morales dependa de una lógica del discurso práctico, mientras que los

${ }^{12}$ Véase J. Habermas, «Ética del discurso», en Conciencia moral y acción comunicativa, traducción R. García Toledano, Barcelona, 1985.

${ }^{13}$ Strawson, Op. cit., cap. I. 
juicios empíricos requieren reflexiones cognitivas que son independientes de la lógica de los discursos teóricos.

Habermas sostiene que el discurso práctico está constituido por las interacciones comunicativas a través de las cuales los participantes coordinan sus planes de comportamiento, argumentando a favor o en contra de diferentes pretensiones de validez con el fin de obtener un cierto consenso acerca de ellas. El principio puente que permite la formación de ese consenso, sirviendo como regla de argumentación es el principio de universalización. Esta no es una mera exigencia gramatical o de consistencia, sino de imparcialidad. Ella estipula que una norma moral es válida en la medida en que puede ganar el asentimiento de todos los afectados.

Habermas se hace cargo de las dificultades para fundamentar este principio de universalización sin caer, como señala $\mathrm{Albert}^{14}$, en el trilema de Münchhausen: o bien un regreso al infinito, o una justificación circular o un corte dogmático en la justificación. Sostiene Habermas que ese trilema se puede eludir si desechamos una concepción deductivista de la fundamentación y siguiendo a Apel buscamos una fundamentación pragmática-trascendental que se apoya en los presupuestos del discurso práctico. Para ello debemos recurrir al concepto de realización contradictoria (o inconsistencia práctica) que se da cuando una acción de habla referida a la proposición $\mathrm{p}$ descansa sobre presupuestos que contradicen a p. Esto constituye un argumento «duro» en la medida en que, como dice R. S. Peters ${ }^{15}$, se trate de discursos tan generales que no cabe sustituirlos por equivalentes funcionales. Habermas intenta mostrar que cuando argumentamos para convencer a otros presuponemos necesariamente el principio de universalización entendido como imparcialidad. Una serie de reglas más específicas de la argumentación que han sido señaladas por autores como Alexy ${ }^{16}$ implican ese principio general.

Según Habermas, un escéptico sólo podría librarse de este presupuesto si se aparta de la comunidad de quienes argumentan. Pero no hay una sola forma vital socio-cultural en el mundo que no esté conectada, por lo menos implícitamente, a una prosecución de la acción comunicativa, por muy rudimentaria y poco institucionalizada que sea. Si alguien pretendiera alejarse

\footnotetext{
${ }^{14}$ Albert (v. Habermas, op. cit.).

${ }^{15}$ Peters (v. Habermas, op. cit.).

${ }^{16}$ Alexy (v. Habermas, op. cit.).
} 
durante un tiempo prolongado de los contextos de acción orientada hacia el entendimiento, se sumiría en un aislamiento tal que se expondría a la esquizofrenia y al suicidio.

Habermas sostiene que el postulado de la universabilidad produce una censura entre lo bueno y lo justo, ya que las cuestiones sobre la vida buena, que constituyen una parte componente de nuestra identidad no pueden ser racionalmente discutibles si no es dentro de cierta forma o estilo de vida.

Este marco general de la concepción metaética de Habermas permite ubicar su posición respecto de la verdad de los juicios morales y del conocimiento de esa verdad. Habermas critica explícitamente a Rawls por suponer que el postulado de imparcialidad se encuentra satisfecho cuando quien formula el juicio moral se sitúa ficticiamente en la posición de cada uno de los afectados; Rawls cree que cada uno, incluyendo por supuesto a un filósofo moral como él mismo puede acometer por su cuenta el intento de justificar las normas fundamentales. Rawls concibe a su propia investigación, no como un aporte a la argumentación, sino como el resultado de una teoría de la justicia. Habermas sostiene, en cambio, que la tarea de la argumentación moral no se puede superar de modo monológico sino que requiere un esfuerzo cooperativo.

Según Habermas, la fundamentación de normas requiere «la realización de un discurso real que, en último término, no es monológico, no tiene nada que ver con una argumentación que se formulara hipotéticamente en el fuero interno» (pág. 88).

En la defensa de esta tesis Habermas entra en polémica con Ernest Tugendhat ${ }^{17}$, quien sostiene que si es cierto, como él cree que lo es, que el postulado de la universalidad no es un criterio semántico sino pragmático y está destinado en consecuencia a ser usado no en el razonamiento monológico, sino en un discurso intersubjetivo real en el que todos los afectados deben determinar si una norma es igualmente buena para ellos, entonces éste no es un postulado para la formación del juicio sino de la voluntad. Tugendhat concibe al discurso como un medio de garantizar que, a través de las reglas de comunicación, todos los afectados tengan la misma oportunidad de participar en una solución de compromiso equitativa, una solución que todos acepten autónomamente. Pero Habermas sostiene que la idea de imparcialidad no puede reducirse a un equilibrio de poderes, requiere el juicio imparcial sobre los intereses de todos los afectados. «En el discurso práctico, los afectados intentan poner en

${ }^{17}$ Tugendhat (v. Habermas, op. cit.). 
claro un interés común mientras que al negociar un acuerdo pretenden compensar intereses particulares y contrapuestos» (pág. 94). Según Habermas, cuando Tugendhat asimila la argumentación con los procesos de formación de la voluntad tiene que pagar el precio de no poder distinguir la validez de la vigencia de las normas morales, ya que el acuerdo efectivo resulta decisivo para la validez de las normas. A esto contrapone su posición según la cual la validez de las normas expresa una voluntad compartida que se remite a un interés general discernible discursivamente.

Estas afirmaciones de Habermas parecen ubicarnos en una posición que, como he sugerido al principio, se podría denominar «constructivismo epistemológico» y que consiste en sostener que si bien la validez de los juicios morales no está dada por el resultado del discurso real sino por sus presupuestos, ese resultado es una forma confiable de conocer los principios válidos. Esto parece estar confirmado por una frase de este tenor de Habermas: «[El discurso práctico] es en realidad un procedimiento no para la producción de normas justificadas, sino para la comprobación de la validez de normas propuestas y establecidas con carácter hipotético» (pág. 128).

Sin embargo, hay otras frases de Habermas que parecen colocarlo en una posición más radical que puede denominarse "constructivismo ontológico»: la posición de que es la validez misma de los principios morales y no el mero conocimiento de esa validez la que se construye con el resultado de la discusión real cuando ella satisface ciertas condiciones. Así Habermas dice, casi a continuación del párrafo anterior que parece apuntar en la otra dirección, que «[los contenidos] se elaboran de tal manera en el discurso que, al final, desaparecen los puntos de vista valorativos que no son susceptibles de acuerdo por consenso» (pág. 129). Asimismo, Habermas sostiene que de «conformidad con la ética discursiva una norma únicamente puede aspirar a tener validez cuando todas las personas a las que afecta consiguen ponerse de acuerdo en cuanto participantes en un discurso práctico (o pueden ponerse de acuerdo) en que dicha norma es válida» (pág. 86). También afirma: «Esta transferencia [del discurso a la acción] no se puede demostrar de la forma en que lo intentan Peters y Apel extrayendo de los presupuestos de la argumentación de modo inmediato normas éticas fundamentales. Las normas fundamentales del Derecho y de la moral no forman parte en modo alguno del campo de la teoría moral; deben considerarse como contenidos precisados de fundamentación en los discursos prácticos. Dado que las circunstancias históricas varían, 
cada época arroja su propia luz sobre las ideas fundamentales práctico-morales. En todo caso, en tales discursos hacemos uso siempre de las reglas de argumentación de contenido normativo; y éstas [no las normas morales] son las que pueden deducirse de modo pragmático trascendental» (pág. 109). Finalmente, Habermas sostiene: «Todos los contenidos, incluso aunque afecten a normas de acción fundamentales, han de hacerse dependientes de discursos reales (o, en sentido sustitutorio que se realizan en sentido advocatorio). El teórico moral puede participar en ellos como afectado y, en su caso, como experto, pero no puede dirigir por su cuenta tales discursos. Una teoría que se extiende a ámbitos de contenido, como la teoría de la justicia de Rawls, debe entenderse como una aportación al discurso que se da entre los ciudadanos...» (pág. 118).

En síntesis, Habermas coincide con Rawls en que hay presupuestos formales, como el de la imparcialidad, que son decisivos para la validez de principios morales. Pero, mientras para Rawls ellos son presupuestos formales del razonamiento moral monológico, para Habermas, ellos son reglas de una práctica social de discurso intersubjetivo. Además, en tanto que para Rawls la validez de los principios morales está dada por la satisfacción de la exigencia de imparcialidad, entre otras, independientemente de que alguien determine que ella está satisfecha, hay razones para pensar que para Habermas esa validez requiere que se haya constituido un consenso de hecho empleando la regla de la imparcialidad. Finalmente, mientras para Rawls parece que uno puede llegar por vía de reflexión individual a la conclusión de que un principio moral es válido, aunque la discusión puede cumplir un rol auxiliar, es claro que para Habermas esto es imposible y que sólo la discusión colectiva, la «búsqueda cooperativa de la verdad» es una vía de acceso confiable al conocimiento moral.

3. En el marco de lo que confusa y vagamente se suele denominar «formalismo», «contractualismo», «constructivismo» o «kantianismo» se pueden distinguir al menos tres tesis ontológicas sobre la constitución de la verdad moral y al menos tres tesis epistemológicas sobre el conocimiento de esa verdad moral. Veamos primero las tesis ontológicas:

O1: La verdad moral se constituye por la satisfacción de presupuestos formales inherentes al razonamiento práctico de todo individuo, en especial el de que un principio moral es válido si es aceptable o no rechazable por todos en condiciones ideales de imparcialidad, racionalidad y conocimiento de los hechos relevantes. 
O2: La verdad moral se constituye por presupuestos formales o procedimentales de una práctica discursiva social destinada a cooperar y evitar conflictos sobre la base de la convergencia de acciones y actitudes dada por el consenso en la aceptación de principios para guiar la conducta. Entre esos presupuestos de la práctica social del discurso moral está el de que un principio es válido cuando es aceptable o no rechazable por todos en condiciones de imparcialidad, racionalidad y conocimiento de los hechos.

O3: La verdad moral se constituye por el consenso que resulta efectivamente de la práctica real de la discusión moral cuando ella es llevada a cabo siguiendo restricciones procedimentales de los argumentos como el de que un principio propuesto debe ser aceptable o no rechazable por todos bajo condiciones ideales de imparcialidad, racionalidad y conocimiento.

Veamos ahora las tesis epistemológicas:

E1: Al conocimiento de la verdad moral -que puede estar constituida de acuerdo a $\mathrm{O} 1, \mathrm{O} 2$ u $\mathrm{O} 3$ pero es sobre todo relevante en los casos $\mathrm{O} 1$ y O2- se accede sólo mediante reflexión individual que, empleando un método de equilibrio reflexivo u otra alternativa, determine si se da la relación apropiada entre presupuestos formales y principios substantivos (y, en el caso de $\mathrm{O} 3$, si se da el consenso efectivo, lo que tendrá que determinarse por observación). La discusión con otros es un auxiliar útil de la reflexión individual, pero en última instancia es inescapable que actuemos de acuerdo a los dictámenes finales de esta última.

E2: La discusión y la decisión intersubjetiva es el procedimiento más confiable de acceso a la verdad moral (sobre todo cuando está constituida por O1 y O2), ya que el intercambio de ideas y la necesidad de justificarse frente a los demás no sólo amplía el conocimiento y permite detectar fallas de razonamiento sino que, principalmente, permite determinar la satisfacción del requisito de atención imparcial de los intereses de todos, bajo el presupuesto de que no hay mejores jueces de los intereses involucrados que los mismos afectados que participan en el proceso colectivo de discusión. Sin embargo, esto no excluye que por vía de la reflexión individual alguien pueda acceder al conocimiento de soluciones correctas, aunque hay que admitir que este método es mucho menos confiable sobre todo por la dificultad para representarse fielmente los intereses de los demás y ser, por lo tanto, imparcial.

E3: El método de discusión y decisión colectiva es la única vía posible de acceso a la verdad moral en el área de justicia, ya que siempre la reflexión monológica se halla distorsionada por 
prejuicios del individuo en favor de sí mismo, Por su condicionamiento contextual y por la dificultad insalvable de ponerse «en los zapatos de otro». Sólo el consenso efectivo obtenido luego de un amplio debate con las menores exclusiones, manipulaciones y desigualdades posibles es una guía confiable para acceder las exigencias de la moral.

Como vimos, Rawls parece sostener la tesis O1 como caracterización de la verdad moral. En efecto, en La teoría de la Justicia el aspecto de práctica social del discurso moral no es absolutamente relevante para las reglas que definen la validez de los principios morales. Aunque todo este desarrollo es sumamente parco y oscuro, Rawls parece suponer, a la Kant, que «la forma de la teoría moral es algo que cada uno tiene en sí mismo» y que se puede ejemplificar con él y con su lector. No parece que sea tampoco relevante para constituir la verdad moral las reglas del discurso monológico sino algo más abstracto e inmaterial que él llama «razonamiento práctico». En obras ulteriores, que aquí como dijimos, no son centralmente tomadas en cuenta, Rawls parece estar más atraído por dar a las prácticas sociales un lugar central, aunque no discrimina entre la práctica del discurso moral y otras prácticas de «una cultura democrática» cayendo tal vez en un convencionalismo), sólo muy recientemente ${ }^{18}$ Rawls parece estar prestando atención a algo más circunscripto, que sintética y enigmáticamente llama «razón pública libre».

En cuanto a su posición epistemológica Rawls, como vimos, parece aceptar E1 aunque -sobre todo en su sección sobre democracia- coquetea tímidamente con E2, la tesis que he denominado «constructivismo epistemológico», para terminar rechazándola, principalmente en lo que se refiere a la determinación de las libertades básicas.

En el caso de Habermas su posición en cuanto a la constitución de la verdad moral parece ser, como acabamos de ver, O3, ya que en diversos párrafos sostiene que no hay principios morales válidos sino como resultado de una discusión moral real llevada a cabo respetando (a exigencia de imparcialidad, que sí puede determinarse a priori de esa discusión. Esto es lo que he llamado «constructivismo ontológico». Sin embargo, hay otras frases, y sobre todo, la discusión con Tugendhat que parecen acercar a Habermas a la tesis O2, según la cual la validez de los principios de justicia está dada por los presupuestos y no por los resultados de la práctica de la discusión moral.

${ }^{18}$ J. Rawls, Free Public Reason. Sin publicar. 
En cuanto a la cuestión epistemológica, no hay duda de que Habermas es un decidido partidario de E3, En efecto, solamente es posible interpretar los párrafos que parecen apoyar a $\mathrm{O} 3$ como si fueran compatibles con $\mathrm{O} 2$ si se sostiene que ellos sólo endosan la tesis E3, o sea, la tesis de que el conocimiento moral sólo se obtiene por la discusión efectiva entre todos los afectados. Los párrafos sobre Rawls son tan terminantes como para descalificar no sólo a E1 sino también a E2: es decir, esos párrafos implican que en ningún caso se puede alcanzar la verdad moral por vía de la reflexión individual, sino a lo sumo, hacer un aporte a la discusión colectiva.

Creo que las tesis más plausibles sobre la constitución y el conocimiento de la verdad moral son $\mathrm{O} 2$ y E2, o sea, tesis intermedias entre las de Rawls (que defiende O1 y se inclina por E1, aunque con una leve simpatía por E2) y Habermas (que se inclina por O3, aunque con cierta confusión con $\mathrm{O} 2$, y defiende $\mathrm{E} 3$ ).

En el plano ontológico, creo que es una grave deficiencia de Rawls, y de su mentor en esta interpretación Kant, que defiende E1, el no incorporar a su enfoque el aspecto de práctica social del discurso moral. Esta incorporación permite hacerse cargo de algún punto fuerte del relativismo respecto de variaciones en cuanto a la práctica de la argumentación moral, sin caer en el callejón sin-salida en el que nos introducimos cuando relativizamos los juicios moral substantivos. Por otra parte, el concentrar nuestra atención en una práctica social permite centrar con una base empírica a partir de la cual inferir las reglas y criterios de hecho presupuestos en aquella práctica. Esto es sobre todo plausible si tomamos en cuenta que esta práctica social tiene funciones manifiestas y latentes -como las de obtener coordinación a través del consenso- y que muchos de los presupuestos formales están adaptados a esas funciones. Finalmente, tomar como base la práctica social efectiva del discurso moral es especialmente importante si uno debe admitir que el discurso tiene presupuestos valorativos substantivos, como el principio de autonomía, ya que ello impide que se alegue que en la defensa de ese principio se incurre en una petitio principii.

En relación a la posición O3, que Habermas parece sostener, creo que por más que algunos consensos efectivos puedan ser descalificados sobre la base del no respeto del postulado de la universalización, en definitiva termina cayendo en un convencionalismo moderado y en la confusión, que él imputa a Tugendhat, entre validez y vigencia. Si el postulado básico está respetado no se ve cómo puede elegirse entre varios posibles consensos y criticarse el efectivamente adoptado en favor de 
otro. Si el postulado de la universalización fuera tan rico como para permitir un solo consenso, esto implicaría caer en $\mathrm{O} 2$, ya que la posición válida estaría definida con antelación a su adopción. Todo esto se relaciona con otro problema más básico: O3 no parece reflejar adecuadamente la fenomenología de la discusión moral, ya que ella consiste, como Rawls y Habermas enfatizan, no en expresar intereses personales, sino principios o pretensiones de validez. Ahora bien, los participantes en la discusión no podrían defender una u otra propuesta como válida si la validez dependiera por definición del resultado de la discusión. Tampoco tiene sentido el ofrecer un principio para la discusión y la decisión si no se alega que hay razones en su apoyo, que es válido, sobre todo cuando se excluye el mero alegato de que va en interés del ofertante. Esto, por supuesto, se aplica también a la concepción de Rawls en la medida que sostiene que las indeterminaciones de los principios de justicia, sobre todo del de diferencia, deben ser resueltas a través del sistema democrático casi como un caso de justicia procesal pura. En síntesis, O3 tiene una tendencia a desembocar en un convencionalismo conservador en cuanto al resultado de la discusión y en una visión de ella como mero choque de intereses en cuanto a su trámite.

$\mathrm{O} 2$ parece, en cambio, absorber lo mejor de los dos mundos. Como O3 se beneficia de la base empírica inherente a su carácter de práctica social con lo que se rompe la circularidad del equilibrio reflexivo, pero no queda atado a los resultados contingentes del consenso efectivo. El que la verdad moral quede definida por sus resultados efectivos permite explicar la argumentación como intentos de conformar estos resultados a aquellos presupuestos. Entre los presupuestos hay posiblemente principios substantivos como el de autonomía del que se pueden deducir juicios morales y reglas procedimentales como la de la imparcialidad, que sirve de filtro de principios y sólo genera éstos en la forma dinámica en que una norma de competencia como las cláusulas constitucionales sobre el poder legislativo, generan leyes.

Si pasamos ahora al plano epistemológico, advertimos que E1, que parece la posición por la que se inclina Rawls, tiene inconvenientes muy serios. Si nuestra reflexión individual es nuestra única forma de acceso a la verdad moral, ¿para qué habríamos de seguir los dictados de una autoridad, aunque ésta sea legítima -como cuando tiene origen democrático- en los casos en que esos dictados se opongan a las conclusiones de esta reflexión? Esta duda es el germen del anarquismo filosófico o de la dictadura ilustrada, según el hecho contingente de que quien se deja guiar por su reflexión individual tenga o no fuerza para 
imponer sus resultados (que seguramente no son sólo autorreferentes). No por casualidad muchos juristas rawlsianos favorecen un amplio poder de los jueces para descalificar las leyes dictadas democráticamente (como dice Walzer ${ }^{19}$, los jueces son los nuevos reyes filosóficos de este tipo de concepción). Esta dificultad de pasar de la autonomía de la moral a la heteronomía del derecho no se salva simplemente diciendo que nuestra reflexión individual nos puede dar razones para obedecer lo que otro ha prescrito, ya que no siempre nos da esas razones y también nos puede dar razones más fuertes en contra de lo prescrito.

Estas deficiencias de E1 dan apoyo a E3 que es la posición de Habermas en caso de que no sea O3. Ella sostiene que tenemos razones para observar lo que surge de la discusión y decisión colectiva, ya que ella es el único método confiable para hallar soluciones moralmente correctas, mientras que la reflexión individual no lo es. De este modo, nuestra reflexión filosófica no moral nos indica que el único método de conocimiento moral es la discusión colectiva. Esto es así no sólo por el beneficio usual de la ampliación de nuestro conocimiento y la detección de nuestros errores de razonamiento que puede prever el intercambio de ideas -lo que sería meramente auxiliar de la reflexión individual-, sino porque en materia moral hay una exigencia que sólo puede detectarse en forma cooperativa, la de imparcialidad. Si partimos de la base de que nadie conoce mejor sus propios intereses que uno mismo y que la expresión de esos intereses tiene un carácter constitutivo del balance de preferencias en conflicto, entonces sólo mediante la efectiva participación de los interesados en el procedimiento de decisión se asegura esa imparcialidad. Cuando se trata del discurso moral originario que sólo se resuelve por consenso unánime, esa imparcialidad parece estar garantizada puesto que la unanimidad es su equivalente funcional. En cambio cuando el discurso moral se institucionaliza y es reemplazado, por razones operativas, por su sucedáneo regimentado que es la democracia como regla de la mayoría, hay que argumentar más para probar que ella garantiza, aunque sea en menor grado, la imparcialidad. Mi impresión es que ella lo hace, contrariamente a lo que dice Rawls, respecto del impacto de la no independencia del voto sobre la imparcialidad, a partir de la restricción que implica la obligación de justificar el propio voto frente a los demás (que descalifica obvios prejuicios motivados por auto-interés) y de la necesidad de obtener el apoyo de cuanta

\footnotetext{
${ }^{19}$ M. Walzer, Spheres of Justice, New York, 1983.
} 
gente sea posible, frente a la posibilidad de que cualquier coalición mayoritaria que haya podido formarse se quiebre por ofertas tentadoras de las minorías marginadas; estos factores crean una tendencia individual a la imparcialidad que se proyecta al nivel colectivo de acuerdo a los lineamientos del teorema de Condorcet.

Pero estos atractivos de E3 se ven neutralizados por rasgos negativos demasiados obvios. Así como E1 parece conducir a un elitismo moral, E3 conduce a un populismo moral: la posición de que lo que resuelven todos o la mayoría es necesariamente correcto. Es evidente que la mayoría a veces se equivoca de gran modo. Por otra parte, al igual que O3, E3 no refleja adecuadamente la fenomenología de la discusión moral, ya que si no es posible acceder por vía de la reflexión individual al conocimiento moral ¿cuál es el aporte que, según Habermas, Rawls haría con su teoría a esa discusión colectiva? ¿Con qué fundamentos podría alguien requerir que se revise el resultado de una discusión colectiva, si ese resultado fuera la única presunción disponible de la verdad moral?

Estos inconvenientes de E3 son salvados por E2 sin caer en los defectos de E1. Según E2 el procedimiento de discusión colectiva constituido por el discurso moral y aun por su sucedáneo imperfecto, el régimen democrático, es el procedimiento más confiable de acceso a la verdad moral, por las mismas razones que apoyan a E3. Pero no es el único. Es posible, aunque generalmente improbable, que por medio de la reflexión individual un sujeto se represente adecuadamente los intereses en conflicto, y que llegue a la conclusión correcta en cuanto a su imparcialidad. Es posible que un individuo aislado en ocasiones llegue a conclusiones más correctas que a las que se llega por el procedimiento colectivo. Esta posibilidad explica el aporte que cada uno puede hacer a la discusión y que pueda legítimamente pedir re-iniciar una discusión concluida por consenso. La probabilidad de que aun por vía de reflexión individual se llegue a una conclusión correcta aumenta cuando ella se refiere a pre-condiciones para la validez del procedimiento colectivo (esta es la materia de los derechos a priori, que es mucho más restringida que la referida por el primer principio de Rawls y que según creo, debe ser el objeto del control judicial de las leyes). Pero dado que en general el procedimiento colectivo es más confiable y que él no operaría si en cada caso decidimos si observar sus resultados o no de acuerdo a los de nuestra reflexión individual, ello justifica la obligación de tal observación aunque nuestra reflexión individual nos indique una respuesta distinta. 
Creo que la combinación de $\mathrm{O} 2$ y E2 -que es, como vimos, una posición intermedia entre las de Rawls y Habermas- constituye la concepción metaética más plausible. Esta es la posición que llamo «constructivismo epistemológico». 